\title{
Cost-Utility Analysis of
} Lipegfilgrastim Compared to Pegfilgrastim for the Prophylaxis of Chemotherapy-Induced Neutropenia in Patients with Stage II-IV Breast Cancer

\section{OPEN ACCESS}

Edited by:

Ye Shen,

University of Georgia, United States

Reviewed by:

Sunita Nair

Capita India Pvt. Ltd., India

Domenico Criscuolo,

Genovax, Italy

*Correspondence:

Esse I. H. Akpo

eakpo@deloitte.com

Specialty section:

This article was submitted to

Pharmaceutical Medicine and

Outcomes Research,

a section of the journal

Frontiers in Pharmacology

Received: 30 June 2017

Accepted: 23 August 2017 Published: 13 September 2017

Citation:

Akpo EIH, Jansen IR, Maes E and Simoens S (2017) Cost-Utility Analysis of Lipegfilgrastim Compared to Pegfilgrastim for the Prophylaxis of

Chemotherapy-Induced Neutropenia in Patients with Stage II-IV Breast

Cancer. Front. Pharmacol. 8:614.

doi: 10.3389/fphar.2017.00614

\author{
Esse I. H. Akpo ${ }^{1 *}$, Irshaad R. Jansen ${ }^{1}$, Edith Maes ${ }^{1}$ and Steven Simoens ${ }^{2}$ \\ ${ }^{1}$ Market Access Strategy and Health Economics, Deloitte (Belgium), Zaventem, Belgium, ${ }^{2}$ Department of Pharmaceutical \\ and Pharmacological Sciences, KU Leuven, Leuven, Belgium
}

Background: Lipegfilgrastim (Lonquex ${ }^{\circledR}$ ) has demonstrated to be non-inferior to pegfilgrastim (Neulasta ${ }^{\circledR}$ ) in reducing the duration of severe neutropenia (SN) in patients with stage II-IV breast cancer. Compared to pegfilgrastim, lipegfilgrastim also demonstrated statistically significant lower time to ANC recovery in cycles 1-3, lower incidence of SN in cycle 2 and lower depth of absolute neutrophil count (ANC) nadir in cycles 2 and 3 . The aim of this study was to quantify the cost utility of lipegfilgrastim compared to pegfilgrastim in stage II-IV breast cancer patients, taking the perspective of the Belgian payer over a lifetime horizon.

Methods: Two Markov models were developed to track on- and post-chemotherapy related complications, including SN, febrile neutropenia (FN), chemotherapy dose delay, chemotherapy relative dose intensity of less than $85 \%$, infection, death rates, and qualityadjusted life years (QALYs). Data on costs (2015 value) and effects were obtained from literature, national references, and complemented by a survey of clinical experts using a modified Delphi method. Both deterministic and probabilistic sensitivity analyses were carried out. Outcomes measures included costs, QALYs and life-years (LY).

Results: At current equivalent price of $€ 1,169$, treatment with lipegfilgrastim was associated with overall costs of $€ 9,845$ vs. $€ 10,208$ for pegfilgrastim and overall QALYs of 13.977 vs. 13.925 for pegfilgrastim. Life expectancy was increased by 21 days (or 0.058 LY gained). The difference in costs stem from avoided infection, SN and FN cases in the lipegfilgrastim compared to the pegfilgrastim group. Similarly, the difference in QALYs was explained by the difference in the number of patients in the chemotherapy/G-CSF Markov state followed by infection and FN between lipegfilgrastim and pegfilgrastim. The probability of lipegfilgrastim to be cost-effective compared to pegfilgrastim was 68,79 , and $83 \%$ at the willingness-to-pay thresholds (WTP) of $€ 10,000, € 30,000$ and $€ 50,000$ per QALY gained, respectively. At a WTP threshold of $€ 30,000$ per QALY gained, lipegfilgrastim was cost-effective up to $€ 1,500$ across all age bands and cancer stages, compared to the current price. 
Conclusions: Lipegfilgrastim is a cost-effective use of health care resources in patients with stage II-IV breast cancer.

Keywords: lipegfilgrastim, pegfilgrastim, breast cancer, cost-utility, febrile neutropenia, severe neutropenia

\section{INTRODUCTION}

Chemotherapy-induced neutropenia (CIN), a common side effect of cancer chemotherapy, is a major risk factor for infection-related morbidity and mortality and a significant doselimiting toxicity (Aapro et al., 2011). The duration and severity of CIN depend on various factors including type of cancer, patient-specific risk factors, individual disease characteristics, and chemotherapy regimen (Crawford et al., 2004). Prolonged and severe CIN may lead to serious complications in the shortterm due to the increased risk of febrile neutropenia (FN) and infections. As a result of CIN, the subsequent chemotherapy cycles may be delayed to allow for neutrophil recovery; or the chemotherapy doses may be reduced in an effort to minimize the incidence of CIN in later cycles (Mucenski and Shogan, 2003). Consequently, when CIN occurs, patient's quality of life is impaired and the long-term clinical efficacy and costeffectiveness of chemotherapy may be compromised (TrilletLenoir et al., 1993; Crawford et al., 2004; Lyman, 2009).

To counteract the negative impact of CIN, short and longacting recombinant granulocyte colony-stimulating factors (GCSFs) are used to promote the proliferation, differentiation, and maturation of neutrophils, thereby reducing the duration and severity of CIN as well as the incidence of severe neutropenia (SN), FN and infection-related mortality (Crawford et al., 1991; Trillet-Lenoir et al., 1993; Kuderer et al., 2007; Wang et al., 2015). The data suggest that long-acting GCSFs are more effective compared to short-acting G-CSFs in terms of incidence of FN (Mitchell et al., 2016). They are also less burdensome to administer (once per cycle with long-acting vs. up to 11 injections with short-acting G-CSFs). Therefore, in Belgium, long-acting -G-CSFs are more often used than short-acting G-CSFs. Current market approved longacting compounds include pegfilgrastim (Neulasta ${ }^{\circledR}$; Amgen Inc.) and lipegfilgrastim (Lonquex ${ }^{\circledR}$; Teva Pharmaceuticals Europe B.V.); with the glycopegylated G-CSF lipegfilgrastim presenting distinct pharmacokinetic and pharmacodynamics properties compared to pegfilgrastim (Hoggatt et al., 2015; Guariglia et al., 2016). Lipegfilgrastim has a slower clearance than pegfilgrastim, with a terminal half-life of lipegfilgrastim shown to be $7-10 \mathrm{~h}$ longer than that of pegfilgrastim in healthy volunteers (Buchner et al., 2014; Guariglia et al., 2016).

In a randomized, multicenter, active-control phase III trial, Bondarenko et al. demonstrated that lipegfilgrastim was as effective as pegfilgrastim in reducing the duration of $\mathrm{SN}$ in patients with breast cancer receiving myelosuppressive chemotherapy in primary prophylaxis (Bondarenko et al., 2013). Wang et al. and Bond et al. further confirmed in meta-analyses that the risk of FN was not significantly different between lipegfilgrastim and pegfilgrastim with an odds ratio (OR) of 0.98
(95\% CI: 0.21-4.53) and a relative risk (RR) of 0.34 (95\% CI: 0.052.14), respectively (Bond et al., 2015; Wang et al., 2015). There were further no differences in hospitalization and antibiotic usage between the two G-CSFs (Gladkov et al., 2016).

However, Bondarenko et al. reported significant lower incidence of SN in cycle 2 of chemotherapy in the lipegfilgrastim group compared to the pegfilgrastim group (8.5\% vs. $21.5 \%$; $P$ $=0.013)$. The absolute neutrophil count (ANC) nadir $\left(10^{9} / \mathrm{L}\right)$ after cycles 2-3 was higher in the lipegfilgrastim group compared to pegfilgrastim group (2.6 vs. 2.0 and 2.5 vs. $2.0 ; P=0.019$ and $P=0.035$, respectively). Similarly, the time to ANC recovery (days) was -1.59 days shorter for the lipegfilgrastim group compared to the pegfilgrastim one $(-1.59,-1.66$, and -1.34; $P=0.003, P=0.008$, and $P=0.033$ for cycles 1,2 , and 3 , respectively). In the lipegfilgrastim group, one patient experienced FN compared to three patients in the pegfilgrastim group. Additionally, 31 patients in the lipegfilgrastim group had their chemotherapy delayed in subsequent cycles with no dose omissions or reductions in cycles $2-4$. In the pegfilgrastim group, 36 patients received delayed chemotherapy treatment, and eight patients had dose omissions or reductions in cycles $2-4$ (Bondarenko et al., 2013).

Cost-effectiveness analysis is increasingly being used to guide resource allocation and maximize health benefits as a result of increasing health expenditures and resulting budgetary constraints. There are very few studies assessing the costeffectiveness of lipegfilgrastim compared to pegfilgrastim. Taking the Belgian payer perspective, Fust et al. concluded that pegfilgrastim was cost-effective vs. lipegfilgrastim in patients with stage II breast cancer using Wang et al.'s risk estimate for FN of $1.39(0.54-3.50)$ for lipegfilgrastim compared to pegfilgrastim (Fust et al., 2015, 2016; Wang et al., 2015). Wang et al.'s risk estimate for FN was derived from a mixed treatment comparison (MTC) using a heterogeneous (i.e., non-breast cancer specific) cancer population and considering different studies designs. Kulikov et al., on the other hand, conducted a comparative pharmacoeconomic analysis of prophylactic use of lipegfilgrastim, pegfilgrastim, filgrastim, and lenograstim in the prevention of FN in Russia's health care setting (Kulikov et al., 2016). Kulikov et al. concluded that lipegfilgrastim was the dominant therapy as it allows to increase the number of patients who responded to prophylaxis of $\mathrm{FN}$ while reducing costs as compared to other G-CSFs. Budget impact analysis, considering the costs for G-CSF drugs, costs for the treatment of incurring cases of $\mathrm{FN}$ and costs for the management of adverse events showed that the use of lipegfilgrastim for the prevention of FN saves budget costs when compared to all other G-CSF drugs over a 1 year time horizon. The data on drugs efficacy (measured as the proportion of responders to prophylaxis of $\mathrm{FN}$ by the end of the first year) was obtained from Bond et al.'s meta-analysis (Bond et al., 2015). 
It should be noted that Bond et al.'s risk estimate for FN was based on a direct comparison between lipegfilgrastim and pegfilgrastim in breast cancer patients and in accordance with the Cochrane Collaboration guidelines (The Cochrane Collaboration, 2011).

The aim of this study was to calculate the cost-utility of lipegfilgrastim as compared to pegfilgrastim in reducing the incidence of CIN and related complications in patients with breast cancer who received a four-cycle chemotherapy regimen of 21 days each. The perspective taken was that of the Belgian third-party payer (the National Institute for Health and Disability Insurance-INAMI/RIZIV) over a lifetime horizon. In contrast to current economic evaluations comparing GCSF vs. non-G-CSFs or long-acting G-CSF (e.g., pegfilgrastim) vs. short-acting G-CSF (e.g., filgrastim) that solely track FN events during chemotherapy cycles (Lyman et al., 2009; Whyte et al., 2011; Fust et al., 2014, 2015; Kulikov et al., 2016), the approach taken in this study broadens the scope to additional CIN complications including incidence of $\mathrm{SN}$, infection and chemotherapy dose delay. These are clinically meaningful outcomes considered in clinical guidelines, health technology appraisals and pharmacoeconomic studies (Aapro et al., 2006; Rutkowski et al., 2010; SMC. Scottish Medicines Consortium, 2011; Therapeutic Goods Administration, 2011; Johnson et al., 2014; Massoudi et al., 2017). In particular, SN has been shown to be significantly associated with both dose delay and relative dose intensity (RDI) less than $85 \%$ (Pettengell et al., 2008).

\section{MATERIAL AND METHODS}

\section{Study Approach}

A mathematical model was developed in Excel (Microsoft Corp., Redmond, WA) to estimate the lifetime costs and qualityadjusted life years (QALYs) for lipegfilgrastim and pegfilgrastim. Two Markov models, one tracking on-chemotherapy cycles and CIN-related complications (model 1) and one capturing the impact of RDI on long-term survival (model 2), compared cumulative costs and outcomes of lipegfilgrastim vs. pegfilgrastim based on two hypothetical cohorts of 1,000 women, aged 59 years old, 38.6, 47.5. and $13.9 \%$ having stage II, III, and IV breast cancer, respectively (proportions based on the relative distribution of patients with high risk stage II, stage III, and IV breast cancer as per the intent-to-treat population in Bondarenko et al., 2013). The models incorporated three sets of data. Clinical data, such as health state transition probabilities, were obtained from Bondarenko et al. and other published studies (Bodey et al., 1966; Leonard et al., 2003; Kuderer et al., 2006; Chirivella et al., 2009; Freifeld et al., 2011; Whyte et al., 2011; Fust et al., 2014; Wang et al., 2015). Transition probabilities and resource use data pertaining to treatment guidelines and clinical practice in a Belgian health care setting were validated or adjusted by Belgian clinicians in a modified Delphi survey. Unit cost data were derived from publicly accessible governmental databases (CBIPBCFI BCfPI, 2015; National Institute for Health and Disability Insurance (RIZIV-INAMI), 2015b).

\section{Model Structure}

The model structure is presented in Figure 1. All patients enter the model in the state labeled "chemotherapy" upon administration of chemotherapy agents, such as docetaxel and anthracycline, and G-CSFs, pegfilgrastim or lipegfilgrastim on day 2 of each chemotherapy cycle. Dependent on risk factors, patients either move to chemotherapy-related complication health states, based on transition probabilities, or remain in their current health state. Patients with SN or infection were considered at risk for chemotherapy delay (Pettengell et al., 2012). Deaths associated with SN, FN and infection were considered in model 1. Post-chemotherapy deaths from breast cancer and other causes were considered in model 2, taking into consideration the impact of RDI (as a result of SN and FN events) on survival. Table 1 summarizes the model parameters.

\section{Clinical Data and Utilities \\ On-Chemotherapy Model (Model 1)}

The model incorporates the incidence of $\mathrm{SN}$ in patients receiving lipegfilgrastm as compared to pegfilgrastim in each cycle of chemotherapy, with a significantly lower incidence of SN for lipegfilgrastim in cycle 2 (8.5 vs. $21.5 \%$; $p$-value $=0.013$; Bondarenko et al., 2013). The risk of FN was estimated for patients with $\mathrm{SN}$ transitioning to $\mathrm{FN}$ and for those at a risk of FN subsequent to chemotherapy (base FN risk). The risk of FN in case of SN was estimated based on the relationship between granulocytes level and infection (Bodey et al., 1966), and the

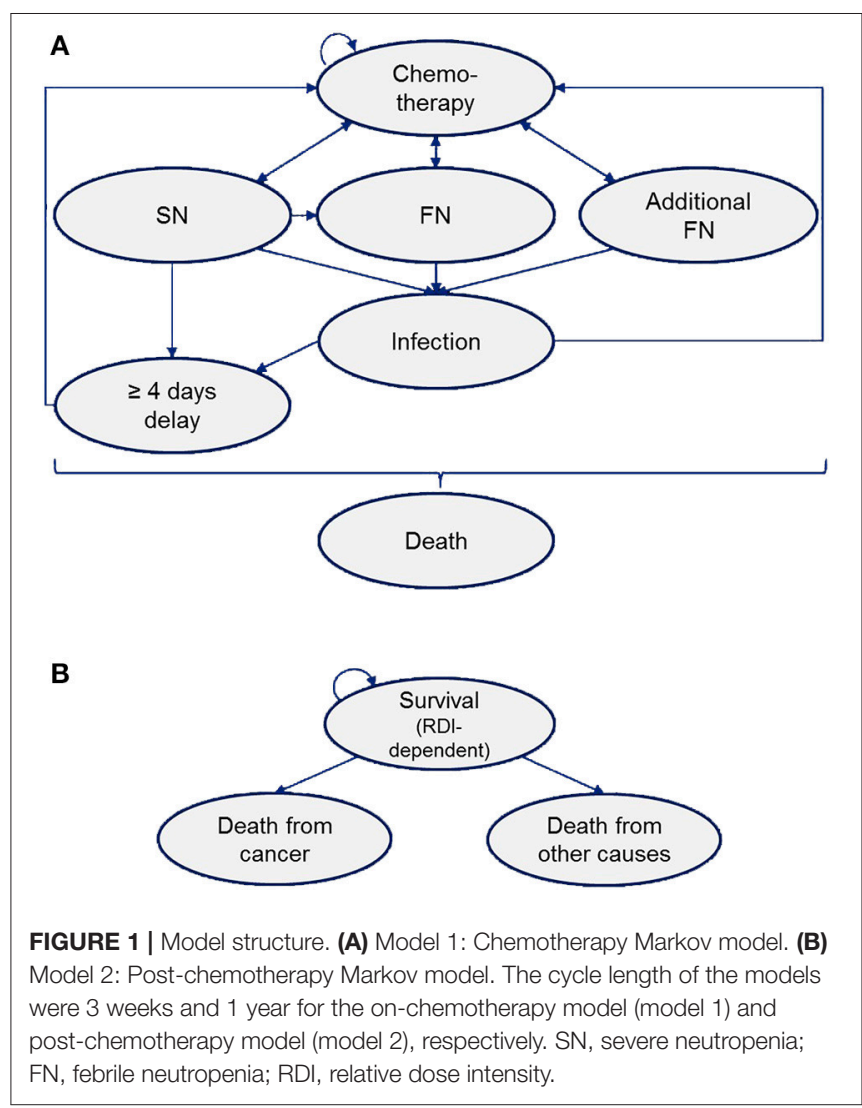


TABLE 1 | Summary of model parameters.

\begin{tabular}{|c|c|c|c|}
\hline Parameter & Base case value & Distribution & Source \\
\hline \multicolumn{4}{|l|}{ Transition Probabilities } \\
\hline Baseline risk of FN associated with pegfilgrastim & 0.032 & Beta (alpha:3.000, beta: 91.000) & Bondarenko et al., 2013 \\
\hline OR of FN with lipegfilgrastim vs. pegfilgrastim & 0.981 & $\begin{array}{l}\text { Log-normal (mean of logs: } \\
-0.020, \text { SD of logs: } 0.750 \text { ) }\end{array}$ & Wang et al., 2015 \\
\hline RR of FN event in chemotherapy cycle $\geq 2$ vs. cycle 1 & 0.213 & $\begin{array}{l}\text { Log-normal (mean of logs: } \\
-1.562, \text { SD of logs: } 0.164)\end{array}$ & $\begin{array}{l}\text { Whyte et al., 2011; Fust } \\
\text { et al., } 2014\end{array}$ \\
\hline \multicolumn{4}{|l|}{ Base Risk of FNa } \\
\hline Cycle 1, lipegfilgrastim vs. pegfilgrastim & 0.019 vs. 0.019 & Based on previous inputs & \\
\hline Cycle 2, lipegfilgrastim vs. pegfilgrastim & 0.004 vs. 0.004 & Based on previous inputs & \\
\hline Cycle 3, lipegfilgrastim vs. pegfilgrastim & 0.004 vs. 0.004 & Based on previous inputs & \\
\hline Cycle 4, lipegfilgrastim vs. pegfilgrastim & 0.004 vs. 0.004 & Based on previous inputs & \\
\hline Risk of additional FN events in subsequent cycles & 9.089 & $\begin{array}{l}\text { Log-normal (mean of logs: } \\
2.188, S D \text { of logs: } 0.196 \text { ) }\end{array}$ & $\begin{array}{l}\text { Whyte et al., 2011; Fust } \\
\text { et al., } 2014\end{array}$ \\
\hline Risk of infection in patients with FN & 0.300 & $\begin{array}{l}\text { Beta (alpha: } 30.811 \text {, beta: } \\
71.893)\end{array}$ & Freifeld et al., 2011 \\
\hline Risk of death in patients with FN & 0.036 & $\begin{array}{l}\text { Beta (alpha: } 25.461 \text {, beta: } \\
3,611.799)\end{array}$ & $\begin{array}{l}\text { Kuderer et al., 2006; Whyte } \\
\text { et al., } 2011\end{array}$ \\
\hline \multicolumn{4}{|l|}{ Risk of SN } \\
\hline Cycle 1, lipegfilgrastim vs. pegfilgrastim & 0.436 vs. 0.511 & $\begin{array}{l}\text { Beta (alpha: } 41.000 \text { vs. } 48.000 \text {, } \\
\text { beta: } 53.000 \text { vs. } 46.000 \text { ) }\end{array}$ & Bondarenko et al., 2013 \\
\hline Cycle 2, lipegfilgrastim vs. pegfilgrastim & 0.085 vs. 0.215 & $\begin{array}{l}\text { Beta (alpha: } 8.000 \text { vs. } 20.000 \text {, } \\
\text { beta: } 86.000 \text { vs. } 73.000 \text { ) }\end{array}$ & Bondarenko et al., 2013 \\
\hline Cycle 3, lipegfilgrastim vs. pegfilgrastim & 0.086 vs. 0.121 & $\begin{array}{l}\text { Beta (alpha: } 8.000 \text { vs. 11.000, } \\
\text { beta: } 85.000 \text { vs. } 80.000 \text { ) }\end{array}$ & Bondarenko et al., 2013 \\
\hline Cycle 4, lipegfilgrastim vs. pegfilgrastim & 0.122 vs. 0.121 & $\begin{array}{l}\text { Beta (alpha: } 11.000 \text { vs. } 11.000 \text {, } \\
\text { beta: } 79.000 \text { vs. } 80.000 \text { ) }\end{array}$ & Bondarenko et al., 2013 \\
\hline \multicolumn{4}{|l|}{ Risk of FN if SN (Based on ANC) ${ }^{b}$} \\
\hline Cycle 1, lipegfilgrastim vs. pegfilgrastim & 0.363 vs. 0.384 & $\begin{array}{l}\text { Gamma (alpha: } 0.900 \text { vs. } 0.600 \text {, } \\
\text { beta: } 1.400 \text { vs. } 1.700 \text { ) }\end{array}$ & $\begin{array}{l}\text { Bodey et al., 1966; } \\
\text { Bondarenko et al., } 2013\end{array}$ \\
\hline Cycle 2, lipegfilgrastim vs. pegfilgrastim & 0.305 vs. 0.313 & $\begin{array}{l}\text { Gamma (alpha: } 1.500 \text { vs. } 1.600 \text {, } \\
\text { beta: } 1.700 \text { vs. } 1.300)\end{array}$ & $\begin{array}{l}\text { Bodey et al., 1966; } \\
\text { Bondarenko et al., } 2013\end{array}$ \\
\hline Cycle 3, lipegfilgrastim vs. pegfilgrastim & 0.335 vs. 0.300 & $\begin{array}{l}\text { Gamma (alpha: } 1.300 \text { vs. } 1.800 \text {, } \\
\text { beta: } 1.900 \text { vs. } 1.100 \text { ) }\end{array}$ & $\begin{array}{l}\text { Bodey et al., 1966; } \\
\text { Bondarenko et al., } 2013\end{array}$ \\
\hline Cycle 4, lipegfilgrastim vs. pegfilgrastim & 0.271 vs. 0.311 & $\begin{array}{l}\text { Gamma (alpha: } 2.500 \text { vs. } 1.800 \text {, } \\
\text { beta: } 1.100 \text { vs. } 1.300 \text { ) }\end{array}$ & $\begin{array}{l}\text { Bodey et al., 1966; } \\
\text { Bondarenko et al., } 2013\end{array}$ \\
\hline \multicolumn{4}{|l|}{ Risk of Chemotherapy Delay if $\mathrm{SN}^{\mathrm{c}}$} \\
\hline Cycle 2, lipegfilgrastim vs pegfilgrastim & 0.238 vs. 0.216 & Based on the Bayes' theorem & $\begin{array}{l}\text { Pettengell et al., 2008; } \\
\text { Bondarenko et al., } 2013\end{array}$ \\
\hline Cycle 3, lipegfilgrastim vs. pegfilgrastim & 0.256 vs. 0.0307 & Based on the Bayes' theorem & $\begin{array}{l}\text { Pettengell et al., 2008; } \\
\text { Bondarenko et al., } 2013\end{array}$ \\
\hline Cycle 4, lipegfilgrastim vs. pegfilgrastim & 0.073 vs. 0.126 & Based on the Bayes' theorem & $\begin{array}{l}\text { Pettengell et al., 2008; } \\
\text { Bondarenko et al., } 2013\end{array}$ \\
\hline \multicolumn{4}{|l|}{ Risk of Infection in Patients with $\mathrm{SN}^{\mathrm{b}}$} \\
\hline Cycle 1, lipegfilgrastim vs. pegfilgrastim & 0.363 vs. 0.384 & $\begin{array}{l}\text { Gamma (alpha: } 0.900 \text { vs. } 0.600 \text {, } \\
\text { beta: } 1.400 \text { vs. } 1.700 \text { ) }\end{array}$ & $\begin{array}{l}\text { Bodey et al., 1966; } \\
\text { Bondarenko et al., } 2013\end{array}$ \\
\hline Cycle 2, lipegfilgrastim vs. pegfilgrastim & 0.305 vs. 0.313 & $\begin{array}{l}\text { Gamma (alpha: } 1.500 \text { vs. } 1.600 \text {, } \\
\text { beta: } 1.700 \text { vs. } 1.300 \text { ) }\end{array}$ & $\begin{array}{l}\text { Bodey et al., 1966; } \\
\text { Bondarenko et al., } 2013\end{array}$ \\
\hline Cycle 3, lipegfilgrastim vs. pegfilgrastim & 0.335 vs. 0.300 & $\begin{array}{l}\text { Gamma (alpha: } 1.300 \text { vs. } 1.800 \text {, } \\
\text { beta: } 1.900 \text { vs. } 1.100 \text { ) }\end{array}$ & $\begin{array}{l}\text { Bodey et al., 1966; } \\
\text { Bondarenko et al., } 2013\end{array}$ \\
\hline Cycle 4, lipegfilgrastim vs. pegfilgrastim & 0.271 vs. 0.311 & $\begin{array}{l}\text { Gamma (alpha: } 2.500 \text { vs. } 1.800 \text {, } \\
\text { beta: } 1.100 \text { vs. } 1.300 \text { ) }\end{array}$ & $\begin{array}{l}\text { Bodey et al., 1966; } \\
\text { Bondarenko et al., } 2013\end{array}$ \\
\hline
\end{tabular}


TABLE 1 | Continued

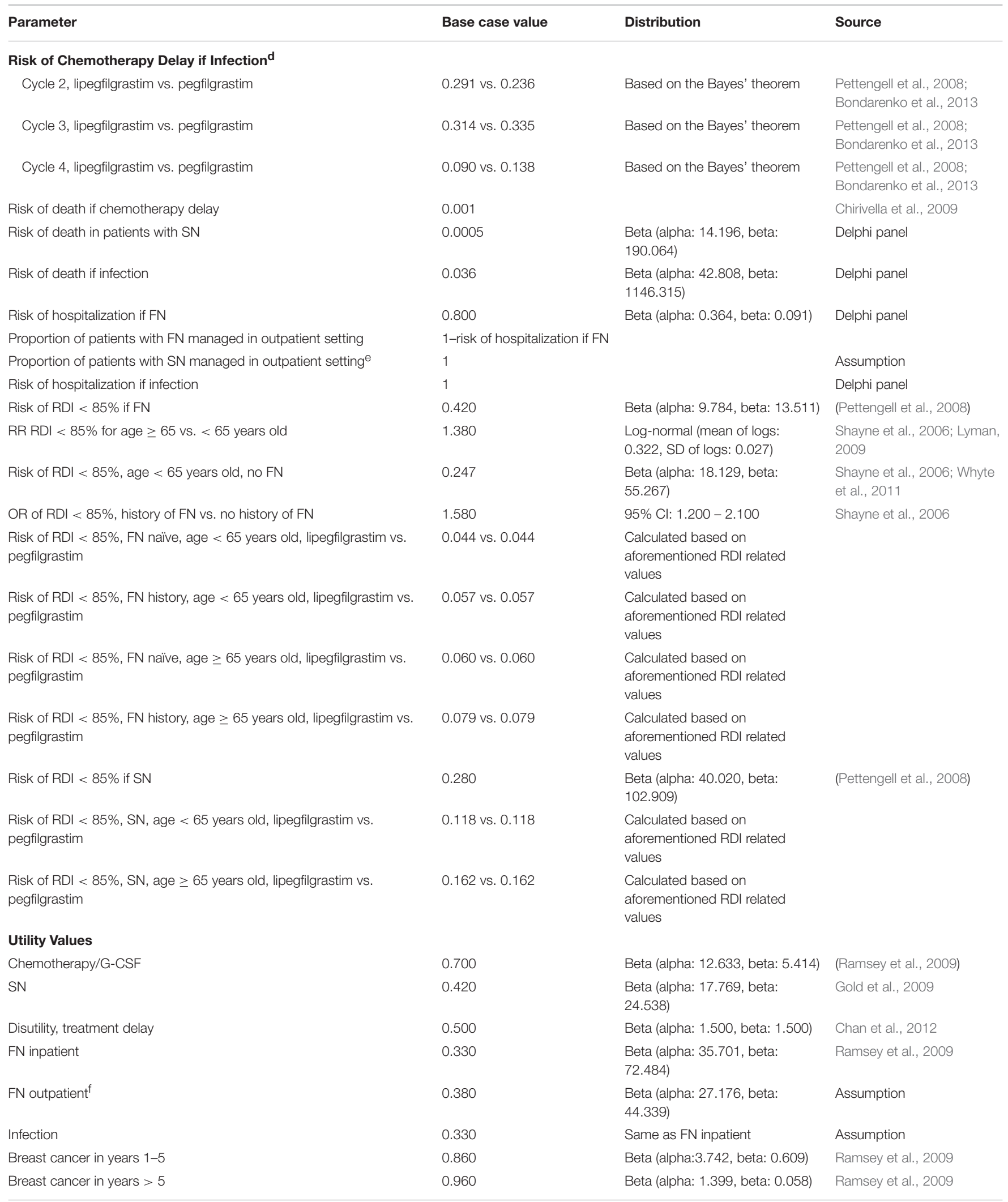


TABLE 1 | Continued

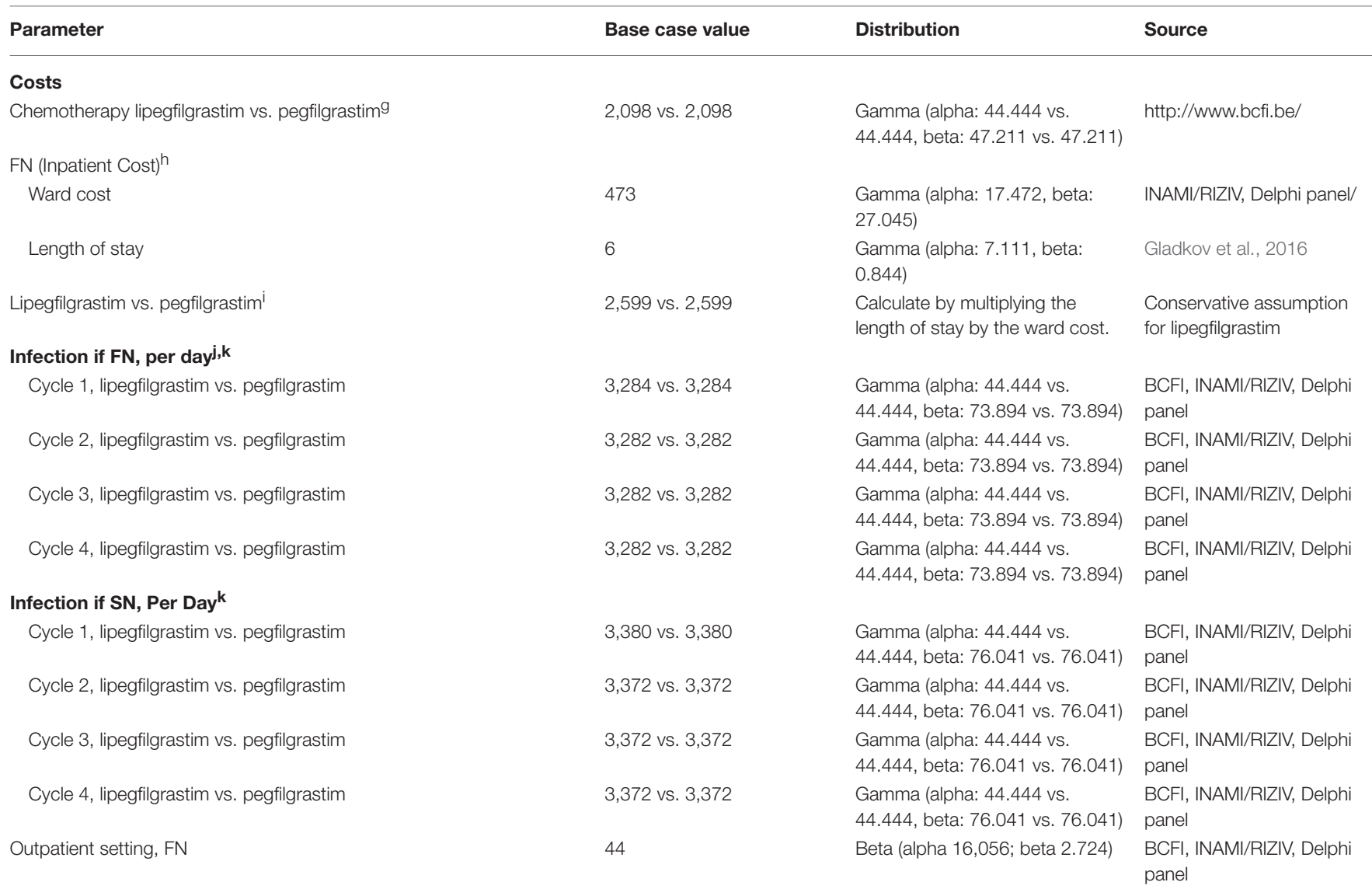

${ }^{a}$ Estimates dependent on the risk estimate used (i.e., RR of 0.981 as per Wang et al., 2015 or OR of 0.340 as per Bond et al., 2015). Calculation are herein based on Wang et al. ${ }^{b}$ A gamma distribution was assigned to the ANC based on the mean ANC published by Bondarenko et al. for lipegfilgrastim and pegfilgrastim and 1,000 iterations were generated. Then, ANC $<0.5 \times 109 / \mathrm{L}$ were used to derived the risk of FN/infection, thanks to the correlation established by Bodey et al. between granulocyte levels and risk of infection. It was then conservatively assumed that the risk of FN is the same as the risk of infection in patients with SN. Patients with SN without fever, signs, or symptoms ofinfection do not receive treatment in the hospital, but are followed up for potential development of fever at home.

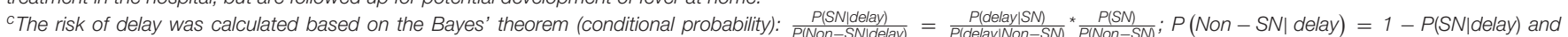
$P($ Non $-S N)=1-P(S N)$. The probability of delay in patients with $S N$ and the probability of delay in patients without $S N$ were as follow: $P($ delay| $S N)=0.42$ and $P($ delay| Non $-S N)$ $=0.32$ (Pettengell et al., 2008). The probability of SN across all cycles was 0.500 and 0.585 for lipegfilgrastim and pegfilgrastim, respectively (Bondarenko et al., 2013).

${ }^{d}$ The same approach as the risk of delay in patients with FN was considered. However, it was assumed that the risk of delay in patients with infection is the same as the risk of delay in patients with FN. The probability of delay in patients with $F N$ and the probability of delay in patients without $F N$ were as follow: $P($ delay $\mid F N)=0.42$ and $P($ delay $\mid$ Non $-F N)=0.32$ (Pettengell et al., 2008). The probability of FN across all cycles was 0.635 and 0.649 for lipegfilgrastim and pegfilgrastim, respectively. These probabilities were calculated from the baseline risk of FN (therefore dependent on risk estimate used as per Wang et al. or Bond et al. - here Wang et al.), the risk of additional FN in subsequent cycles and the estimated risk of FN in patients with SN.

${ }^{e}$ Patients with SN without fever, signs, or symptoms ofinfection do not receive treatment in the hospital, but are followed up for potential development of fever at home. No cost was imputed for the management of $\mathrm{SN}$ in the outpatient setting.

${ }^{f}$ The difference (i.e., 0.05) between utilities for patients hospitalized for FN vs. those treated in an outpatient setting as per Lathia et al. (2013) was simply applied.

9 Treatment costs were composed of the unit cost of G-CSF (lipegfilgrastim or pegfilgrastim) : €1,169; cost of chemotherapy agents docetaxel (20 mg/ml): €68; and doxorubicine TEVA (10 mg/5 ml): $€ 8$ (CBIP-BCFI BCfPI, 2015); and G-CSF administration cost: $€ 8$ (Annemans et al,, 2001). G-CSF administration costs were inflated to 2015 using the Harmonized Index of Consumer Price for Health (Federal Reserve Bank of St.Louis, 2015). Chemotherapy agent related costs were adjusted to a female patient with a BMI of $26 \mathrm{~kg} / \mathrm{m}^{2}$ and a weight of $73.9 \mathrm{~kg}$.

"Of note, in the model, the costs of empirical antibiotic treatment was also considered. If a patient is admitted at the hospital with FN, "empiric" antibiotic therapy is initiated at admission. Piperacilline-tazobactam $4 \times 4 \mathrm{~g} / \mathrm{d}$ is commonly used and treatment is stopped when until restitution of neutrophils $>1,000 / \mathrm{mm}^{3}$ AND free of fever after $48 \mathrm{~h}$ AND negative bacterial cultures. Median time of treatment duration with piperacilline-tazobactam for breast cancer patients is 4 days. The ward cost was calculated as the average of the daily cost for all Belgian hospitals.

iThe time in hospital, day, mean (SD) was 1 (0) and 5.5 (0.7) for lipegfilgrastim and pegfilgrastim based on the Bondarenko head-to-head trial, respectively (Gladkov et al., 2016). This would have resulted in FN hospital costs of 473 vs. 2,599 for lipegfilgrastim vs. pegfilgrastim. Because the only patient who was hospitalized for FN was excluded for protocol violation (Bondarenko et al., 2013), we conservatively assumed that the length of stay for lipegfilgrastim would be the same as of pegfilgrastim. The value of 5.5 days was rounded up to 6 days. jThe duration of antibiotic use was considered to be 5 days for both treatment arms given that no significant difference in antibiotic use have been demonstrated between the two G-CSFs (Bondarenko et al., 2013; Mhaskar et al., 2014; Gladkov et al., 2016).

${ }^{k}$ Weighted average calculated based on the following prevalence of infection: bacteremia: 60.0\%, sepsis: $22.5 \%$, pneumonia: $8.1 \%$ and fungal infection: $9.4 \%$ (assumption).

BCFI, Belgian Centre for Pharmacotherapeutic Information; FN, febrile neutropenia; OR, odds ratio; RR, relative risk; SN, severe neutropenia. The transition probabilities were validated in a modified Delphi panel and are reflective of current clinical practice and management of chemotherapy-induced neutropenia and related complications in patients with breast cancer in Belgium. 
probability of ANC less than $0.5 \times 10^{10} / \mathrm{L}$ (Bondarenko et al., 2013). It was then conservatively assumed that the risk of FN is the same as the risk of infection.

The base risk of FN for lipegfilgrastim was calculated from the risk of $\mathrm{FN}$ in the pegfilgrastim group to which was applied a risk estimate for FN for lipegfilgrastim vs. pegfilgrastim. This adjustment was considered appropriate given that in the Bondarenko study, the only patient who had FN in the lipegfilgrastim arm was excluded for protocol violation (Bondarenko et al., 2013). As mentioned earlier, two metaanalyses reported two different risk estimates for FN for lipegfilgrastim vs. pegfilgrastim. Wang et al. reported an OR of 0.98 (95\% CI: 0.21-4.53) based on a direct comparison between lipegfilgrastim and pegfilgrastim in breast cancer patients. The indirect comparison included trials vs. placebo or no-G-CSF in different patient populations (breast cancer, colorectal cancer, non-Hodgkin lymphoma, lung and ovarian cancer), resulting in an OR of 2.00 (95\% CI: 0.47-8.11). The result of the combination of direct and indirect comparisons was between the results of the direct and the indirect comparison, with an OR of 1.39 (0.54-3.50) (Wang et al., 2015). Bond et al., on the other hand, reported a RR of 0.34 (95\% CI: 0.05-2.14) in a direct comparison between lipegfilgrastim vs. pegfilgrastim (Bond et al., 2015). Given (i) the recommendations of the Cochrane Handbook for Systematic Reviews of Interventions stating that direct comparison should take precedence over indirect comparison in forming conclusions (The Cochrane Collaboration, 2011), (ii) the application of inconsistent indirect or mixed methods by Wang et al. that led to potentially biased risk estimates not in the alignment with the head to head trial results (Lehmacher et al., 2016), risk estimates from direct comparison in breast cancer patients were considered relevant in the current study. The base analyses were performed using an OR of 0.98 (95\% CI: $0.21-4.53)$ and a RR of 0.34 (95\% CI: 0.05-2.14). All other transition probabilities were derived from literature or adjusted for lipegfilgrastim and pegfilgrastim wherever needed.

\section{Post-Chemotherapy Model (Model 2)}

RDI is the ratio of the actual dose of chemotherapy delivered to the intended dose of the standard chemotherapy regimen over a specific time. Decreases in RDI can be results of dose delays and dose reductions. Although controversial, the relationship between RDI and patient outcomes is well described in the literature (Bonadonna et al., 2005; Pettengell et al., 2008; Bretzel et al., 2009; Chirivella et al., 2009; Aapro et al., 2011); and several studies address the significance of achieving an RDI of more than 85\% (Bonadonna et al., 2005; Lyman, 2008). Age, SN and FN are predictors of receiving RDI less than $85 \%$ (Shayne et al., 2006; Pettengell et al., 2008; Whyte et al., 2011). Gladkov et al. reported that at least $98 \%$ of patients in the lipegfilgrastim and the pegfilgrastim received the planned chemotherapy dose (Gladkov et al., 2016). Consequently, the risk of RDI less than $85 \%$ was assumed to be the same for both G-CSFs (Pettengell et al., 2008). It was further adjusted for age, incidence of $\mathrm{SN}$, incidence of FN and FN history (Leonard et al., 2003; Shayne et al., 2006; Chirivella et al., 2009; Lyman et al., 2009; Whyte et al., 2011).
The impact of RDI on survival was considered next. The estimation of the risk of death if RDI less than $85 \%$ was as per Whyte et al.'s formula that is based on the risk of RDI less than $85 \%$ when experiencing neutropenic events and the survival hazard ratio (Whyte et al., 2011). The literature suggests that for anthracycline-based regimens, $32 \%$ of patients who experienced neutropenic events receive RDI less than $85 \%$, compared with $7 \%$ for those who do not experience these events (Leonard et al., 2003). Additionally, a hazard ratio of 1.32 was seen for survival associated with an $\mathrm{RDI} \geq 85 \%$ vs. an $\mathrm{RDI}<85 \%$ (Lyman et al., 2009). The model applies this hazard ratio to the survival of patients with low RDI in the first 5 years of the post-chemotherapy model. After and for the remainder of their lifetime, all-cause mortality as per the general population applied as it was assumed that breast cancer survivors were cured after 5 years. Breast cancer specific mortality data by stage and age were obtained from the Belgian Cancer Registry and all-cause mortality data from Belgian life tables (data on file).

\section{Utility Values}

Health utilities, which vary between 0 (death) and 1 (ideal health) were used to calculate the QALYs. Utility values were obtained from the literature for breast cancer during chemotherapy, $\mathrm{SN}$, $\mathrm{FN} /$ infection, breast cancer survivor during years one to five and breast cancer survivor after year five (Table 1). A disutility factor was assigned to treatment delay. QALYs were calculated by multiplying life years gained over the course of the chemotherapy and post-chemotherapy models by utility values.

\section{Resource Use and cost Data Delphi Panel Survey}

Resource use data were obtained from a random selection of 64 oncologists and hematologists through a modified Delphi survey methodology. The Delphi survey was conducted in two consecutive rounds. Based on identified treatment pathways, a questionnaire was developed with closed-ended questions about medication, laboratory tests, and diagnostic procedures and open-ended questions about additional information (e.g., to obtain empirical data as opposed to protocol-driven clinical research data). In the first round, the survey was conducted via a web-based application, SurveyMonkey ${ }^{\circledR}$, yielding 11 responses out of 64 experts recruited. The results were analyzed as median, 25 th, and 75 th percentile outcomes. In the second round, results obtained were presented to the 11 participating respondents via email or by means of a face-to-face interview to validate/adjust the results, yielding 7 responses with narrower variances between outcomes.

\section{Costs Associated with Severe Neutropenia, Febrile Neutropenia, Infection and Delay}

Resource use related to: G-CSFs (lipegfilgrastim and pegfilgrastim), medication (antibiotics and antifungals), chemotherapy regimen, laboratory tests, diagnostic procedures (e.g., X-ray, CT-scan), type and duration of hospitalization (e.g., emergency room, oncology ward) were taken into account. Medical procedures related costs were obtained from the Nomensoft database on the INAMI/RIZIV website (National 
Institute for Health and Disability Insurance (RIZIV-INAMI), 2015a). Drug cost data (in 2015 euros - $€$ ), which were derived from the Belgian Center of Pharmacotherapeutic Information website (CBIP-BCFI BCfPI, 2015), were collected for the drugs currently prescribed for the treatment of SN, FN and associated complications. The modified Delphi survey yielded data about the use of antibiotics and antifungals for the four most common infections following SN and FN, being bacteremia, sepsis, pneumonia, and fungal infections (Kuderer et al., 2006). An average antibiotics treatment duration of 5 days for hospitalized patients with FN was considered in both treatment arms (Mhaskar et al., 2014). Treatment costs for antibiotics and anti-fungal medication were computed as a weighted average of the cost per treatment course, taking relative market share into consideration.

The per diem cost of hospitalization was computed from data obtained from the NIHDI website (National Institute for Health and Disability Insurance (RIZIV-INAMI), 2015b) taking the mean of all listed acute care facility admission costs in Belgium. Daily costs for hospital stay, laboratory and microbiological tests as well as radiology procedures were calculated and adjusted to length of stay.

With respect to $\mathrm{FN}$, inpatient and outpatient costs were considered. The hospitalization length of stay was derived from Gladkov et al. (2016), whilst it was assumed that the risk of hospitalization was similar between the two G-CSFs and did not differ between cycles. With the FN outpatient costs, it was assumed that patients were treated for seven to 10 days with per oral amoxicillin/clavulanic acid $2 \times 2$ g/day as per the clinical practice (data on file).

Finally, there were no costs imputed for the management of SN (only in the outpatient setting) and of chemotherapy delay. There were also no costs associated with the post-chemotherapy model.

\section{Base Case Analysis}

Model parameters base values were defined and differences on costs and QALYs between the lipegfilgrastim group and the pegfilgrastim group calculated. The incremental cost-effectiveness ratio (ICER), calculated as the ratio of the incremental costs to the incremental QALYs between lipegfilgrastim and pegfilgrastim, was calculated when appropriate. Analyses were performed over a lifetime horizon. Costs and QALYs were discounted at a rate of 3 and 1.5\%, respectively following guidelines of the Belgian Health Care Knowledge Centre (KCE) (Cleemput et al., 2012). Effectiveness was also reported in terms of life-years gained (LYG) that were not discounted since they were expected to be valuable in the future as at present. In comparison to LYG, QALYs involve both quantitative and qualitative components that are likely to be less valuable in the future as at present, and are also likely to be subject to higher uncertainty (Peura et al., 2008).

\section{One-Way Sensitivity Analysis}

One-way sensitivity analysis (OWSA) and probabilistic sensitivity analyses (PSA) were conducted to test both parameter and model uncertainty. In the OWSA, sensitivity ranges of parameters included either 95\% CIs, where data was available, or the estimated variability of $\pm 30 \%$ of the mean value. Tornado diagrams were used to present the results of the OWSA and to depict the parameters that mostly affect both costs and QALYs. With the PSA, the impact of joint uncertainty among all input parameters on cost-effectiveness outcomes was captured by assigning a probability distribution to each parameter and using 5,000 random samples from parameter distributions. A cost-effectiveness acceptability curve (CEAC) was subsequently drawn, showing the probability of lipegfilgrastim being costeffective for various levels of willingness to pay (WTP) per QALY gained.

\section{Price Threshold Analysis}

A price threshold analysis was subsequently conducted to determine the upper limit of the price of lipegfilgrastim to be considered cost-effective, using a WTP of $€ 30,000$ per QALY gained (corresponding approximately to the Belgian Gross Domestic Product). The analysis was carried out across breast cancer stages and age bands of $35-45,45-55,55-65,65-75$, and over 75 years. The analysis was based on the net monetary benefit, which is the difference between monetized benefits and costs between lipegfilgrastim and pegfilgrastim. Interventions with a positive net monetary benefit are deemed cost-effective as the associated cost is less than the value of the additional benefit achieved.

\section{RESULTS}

\section{Base Case Analysis}

The average costs and QALYs of primary prophylaxis with lipegfilgrastim compared to pegfilgrastim for patients with stages II-IV breast cancer are presented in Table 2 Cost-effectiveness results. Results are presented for an OR of 0.98 and a RR of 0.34 for the risk of $\mathrm{FN}$ for lipegfilgastim compared to pegfilgrastim. With an OR of 0.98 , the average costs per patient and QALYs for lipegfilgrastim were $€ 9,845$ and 13.977 compared to $€ 10,208$ and 13.925 for pegfilgrastim. Life expectancy in the lipegfilgrastim group was further increased by 0.058 years on average (i.e., 21 life-days gained) compared with pegfilgrastim. Similarly, when using a RR of 0.34 , lipegfilgrastim was the dominant strategy with lower costs and higher QALYs compared to pegfilgrastim. In the analysis of LYG, an average increase by 0.059 years (i.e., 22 life-days gained) was estimated in the lipegfilgrastim group compared to the pegfilgrastim group. Overall, these results indicated that lipegfilgrastim was a dominant strategy in the base case. Consequently, the ICER was not calculated. Given the consistency in conclusions when using either an OR of 0.98 or a RR of 0.34 for the risk of FN for lipegfilgrastim compared to pegfilgrastim, following results will be limited to the analyses conducted with an OR of 0.98 .

In deterministic analyses, $41 \%$ of the cost-savings came from avoided infection cases and associated costs when comparing lipegfilgrastim with pegfilgrastim. Twenty eight percent of the cost-savings were associated with avoided SN cases, $21 \%$ with avoided FN cases and 10\% with avoided 
TABLE 2 | Cost-effectiveness results for lipegfilgrastim compared to pegfilgrastim.

\begin{tabular}{|c|c|c|c|c|c|c|}
\hline & \multicolumn{3}{|c|}{$\begin{array}{c}\text { Results based on Wang et al.'s risk estimate for FN, } \\
\text { lipeg vs. peg: } \mathrm{OR}=0.98 \text { ) }\end{array}$} & \multicolumn{3}{|c|}{$\begin{array}{c}\text { Results based on Bond et al.'s risk estimate for FN, } \\
\text { lipeg vs. peg: } R R=0.34 \text { ) }\end{array}$} \\
\hline & Costs $(€)$ & QALYS & LY & Costs $(€)$ & QALYS & LY \\
\hline Lipegfilgrastim & 9,845 & 13.977 & 21.204 & 9,796 & 13.997 & 21.210 \\
\hline Pegfilgrastim & 10,208 & 13.925 & 21.145 & 10,205 & 13.944 & 21.151 \\
\hline Difference & -363 & 0.052 & 0.058 & -410 & 0.054 & 0.059 \\
\hline
\end{tabular}

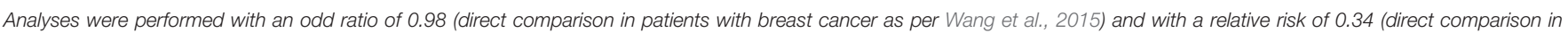

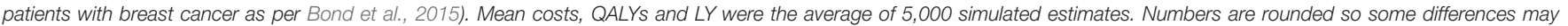
appear to be off. LY, life years; OR, odds ratio; $Q A L Y S$, quality-adjusted life years gained; $R R$, relative risk.

chemotherapy delay. Conclusively, there were fewer patients who experienced CIN-related complications and associated costs in the lipegfilgrastim group compared to the pegfilgrastim group. The chemotherapy/G-CSF costs were offset by higher costs associated with CIN-related complications; and particularly with infection. The difference in QALYs was attributable to the difference in the number of patients in the chemotherapy/ G-CSF Markov state followed by infection, FN, SN and chemotherapy delay.

\section{One-Way Sensitivity Analysis}

The impact of each of the model parameter on incremental costs and QALYs was explored in OWSA (Figure 2). For all scenarios within the possible ranges of model inputs, lipegfilgrastim remained less costly compared to pegfilgrastim; except when increasing the cost of lipegfilgrastim by $30 \%$. The cost of lipegfilgrastim had the largest impact on the incremental costs, followed by the risk of $\mathrm{FN}$ in patients with $\mathrm{SN}$ in cycle 1 for lipegfilgrastim and the risk of SN following chemotherapy in cycle 1 for lipegfilgrastim. Incremental QALYs were most sensitive to variance in age, in the proportion of patients with stage III and II breast cancer and in the utility value for cancer survivors after year five. Overall, QALYs gained decreased as age increased; and increased as the proportion of patients with stage III and II breast cancer increased. Additionally, QALYs gained increased as the utility for cancer survivors after year five increased.

The effect of joint parameter uncertainty on outcomes is illustrated in the cost-effectiveness plane. Figure 3 shows that lipegfilgrastim was associated with greater QALYs in $87 \%$ of the 5,000 simulations (northeast and southeast quadrants), and in over half of the simulations, lipegfilgrastim was dominant (southeast quadrant). Figure 4 indicates that the likelihood that lipegfilgrastim is cost-effective vs. pegfilgrastim increases as the WTP increases (i.e. gains in QALYs become increasingly rewarded), reaching 68,79 , and $83 \%$ at the WTP thresholds of $€ 10,000, € 30,000$, and $€ 50,000$ per QALY gained, respectively. The probability that lipegfilgrastim is cost-saving is indicated by the probability at a WTP of zero (where no value is placed on the health benefits), which was $57 \%$.

\section{Price Threshold Analysis}

Figure 5 shows that at currently equivalent price with pegfilgrastim, lipegfilgrastim is dominant across all cancer stages and age bands. Lipegfilgrastim remained cost-effective across all cancer stages and age bands up to a price point of $€ 1,500$ at a WTP of $€ 30,000$ per QALY gained. Between $€ 1,500$ and $€ 2,000$, lipegfilgrastim is cost-effective in some age groups and is no longer cost-effective in all cancer stages and age bands at a price higher than $€ 2,000$.

\section{DISCUSSION}

Long-acting G-CSFs, lipegfilgrastim, and pegfilgrastim, are administered once per chemotherapy cycle to reduce the duration of SN and the incidence of FN. This study evaluated the cost-utility of lipegfilgrastim compared to pegfilgrastim, with a particular focus on the following outcome measures: incidence of $\mathrm{SN}$, incidence of FN, infection, chemotherapy dose delay and RDI less than $85 \%$. In addition, QALYs and LYs gained were captured as standard measures of effect.

This analysis has demonstrated that lipegfilgrastim is a more cost-effective strategy compared to pegfilgrastim over the lifetime of patients with stage II-IV breast cancer. The cost-savings came merely from the decrease in infection and SN cases. OWSA further indicated that cost-savings were sensitive to the risk of FN in patients with $\mathrm{SN}$ and the risk of SN following chemotherapy in cycle 1. Overall, these results align with the literature, which shows that SN places patients at high risk of infection and the risk of FN increases in direct proportion to the severity and duration of neutropenia and occurs most frequently early in a course of chemotherapy (Lyman et al., 2003; Lyman and Rolston, 2010; Freifeld et al., 2011; Saloustros et al., 2011). In our study, the risk of FN/infection in patients with $\mathrm{SN}$ was based on the relationship between granulocyte levels and the risk of infection as established by Bodey et al. in patients with acute leukemia (Bodey et al., 1966). Therefore, further studies on the relationship between granulocyte or ANC levels and the risk of FN/ infection in patients with breast cancer may be important. This could further be relevant when considering that lipegfilgrastim is associated with higher neutrophil count at the end of a chemotherapy cycle than pegfilgrastim (Bondarenko et al., 2013); suggesting that fewer patients might be at a risk of developing $\mathrm{FN}$ or to experience $\mathrm{SN}$ in subsequent chemotherapy cycles. Indeed, this was observed in the second chemotherapy cycle in Bondarenko et al.'s study. Finally, it should be mentioned that cost-savings were influenced the most by the variation 

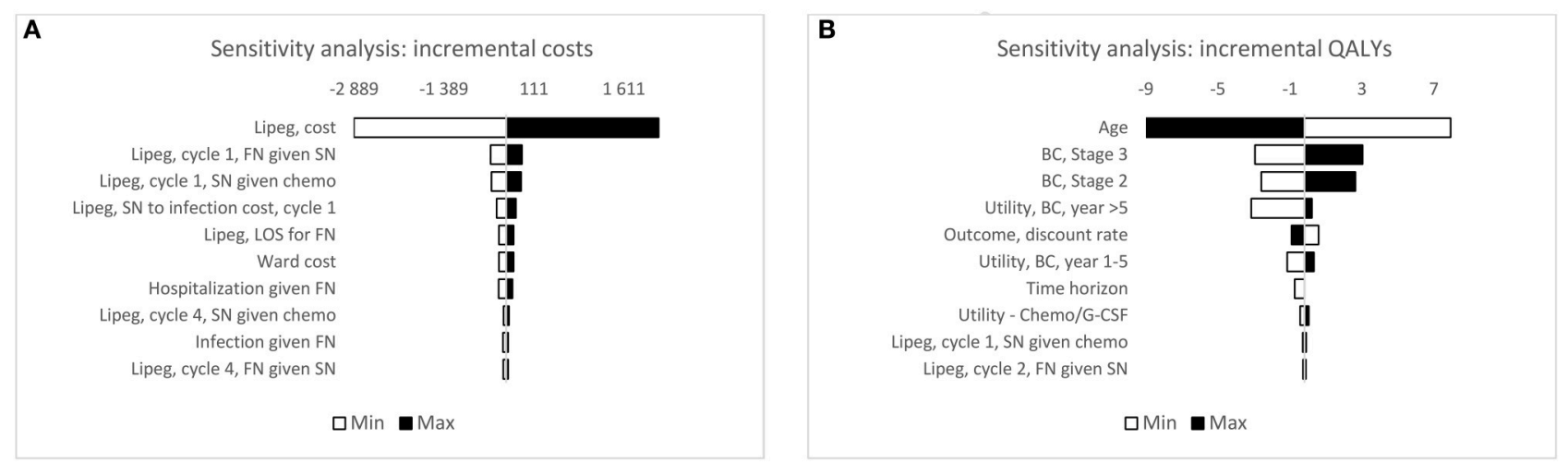

FIGURE 2 | One-way sensitivity analysis for incremental cost and QALY. Tornado diagram displaying the results of the one-way sensitivity analysis. The diagram shows the correlation between $\pm 30 \%$ variation in model parameters and the distribution of costs and QALYs. Only the top 10 influential parameters of the incremental costs and QALYS are displayed. BC, breast cancer; chemo, chemotherapy; FN, febrile neutropenia; G-CSF, granulocyte colony-stimulating factor; lipeg, lipegfilgrastim; QALYs, quality-adjusted life years; SN, severe neutropenia.

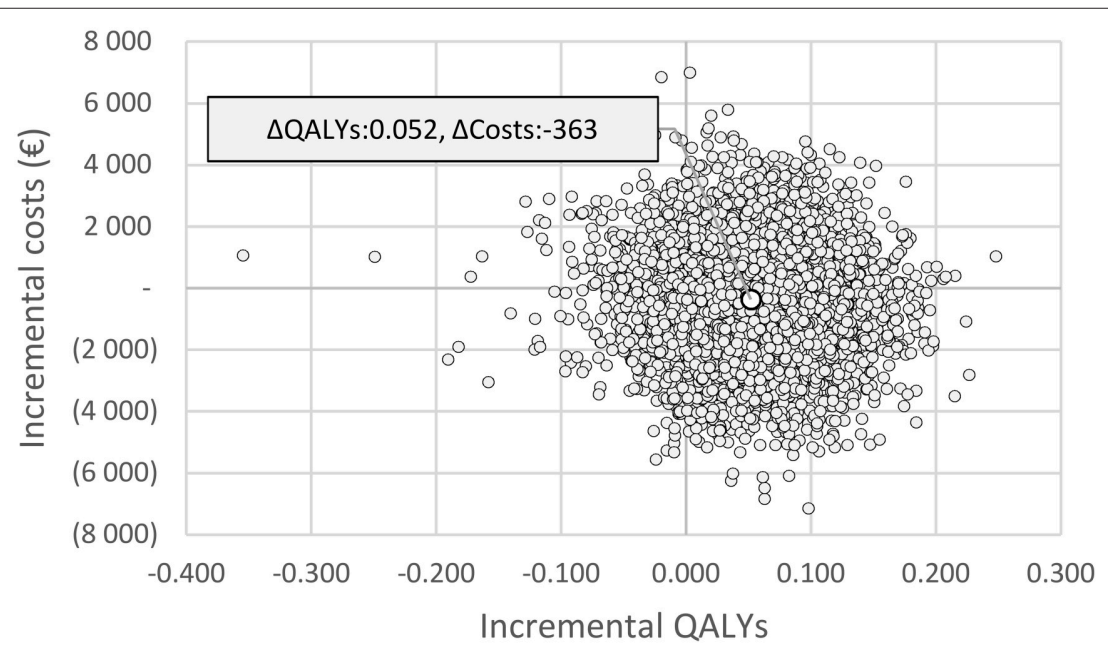

FIGURE 3 | Cost-effectiveness plane for lipegfilgrastim compared to pegfilgrastim. Plot of the results of the probabilistic sensitivity analysis for 5,000 simulations. The $x$-axis represents the difference in QALYS and the Y-axis the difference in costs between lipegfilgrastim and pegfilgrastim. Seven percent of the estimates lie in the north-west quadrant (pegfilgrastim dominates), $36 \%$ in the north-east quadrant (lipegfilgrastim is more effective but more expensive), $7 \%$ in the south-west quadrant (lipegfilgrastim is cheaper but less effective) and $51 \%$ in the south-east quadrant (lipegfilgrastim dominates pegfilgrastim). Simulations spanned all four quadrants of the cost-effectiveness plane, indicating some level of uncertainty around the base case estimate (cost-savings of €363 and QALYs gained of 0.052). $\triangle$ QALYs, incremental quality-adjusted life years; $\Delta$ Costs, incremental costs.

in the cost of lipegfilgrastim. In Belgium, lipegfilgrastim and pegfilgrastim have the same price. The price threshold analysis suggested that lipegfilgrastim is cost-effective up to $€ 1,500$ across all age bands and cancer stages, compared to the current price of $€ 1,169$.

Effectiveness results were largely influenced by the patient age, breast cancer stage at diagnosis and the utility value for cancer survivors after year five. This was in line with previous costeffectiveness studies reporting on these parameters as drivers of the cost-effectiveness of G-CSFs for the prevention of FN after chemotherapy (Lyman, 2009; Ramsey et al., 2009; Whyte et al., 2011). The impact of age on the cost-effectiveness results was expected given the age-dependent risk of RDI less than $85 \%$
(Shayne et al., 2006) and the relative impact on overall mortality. Further research on utility weights associated with breast cancer survivors after year five is required given the sensitivity of different cost-effectiveness studies on this parameter.

In a European survey relating to cancer therapy and neutropenic infections, Leonard reported that oncology nurses recognize that minimizing the risk of infection and FN as being important for achieving a successful outcomes in cancer therapy (Leonard, 2012). From a patient perspective, the majority reported having their chemotherapy delayed or changed as a result of neutropenia, infection or FN. Therefore, despite being broaden to major CIN-related complications, the value of our model derives merely from the most serious chemotherapy 


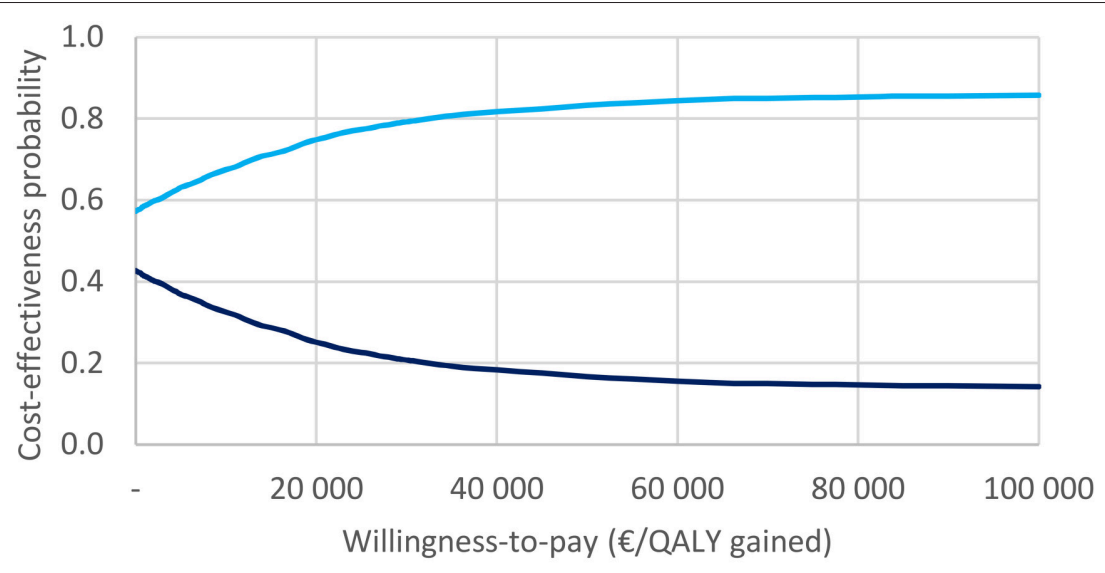

— Lipegfilgrastim — Pegfilgrastim

FIGURE 4 | Cost-effectiveness acceptability curve.

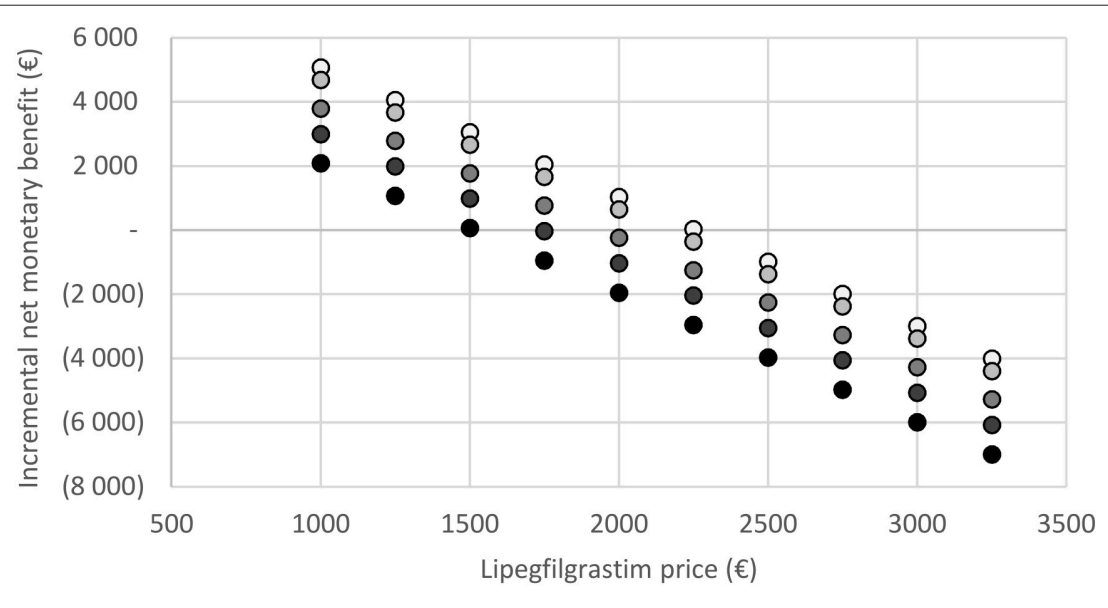

OAge 35 OAge 45 OAge 55 OAge 65 -Age 75

FIGURE 5 | Price threshold analysis. Lipegfilgrastim price was varied across breast cancer stages and age bands of 35-45, 45-55, 55-65, and over 75 years old to examine efficient reimbursement prices. The analysis was conducted at a willingness to pay threshold of $€ 30,000$ per QALY gained. Each dot represents an incremental net monetary benefit value for a specific age at a given price point. Of note, the analysis was conducted keeping the following distribution of breast cancer stage constant: stage II: $38.6 \%$, stage III: $47.5 \%$ and stage IV: $13.9 \%$. Positive incremental net monetary benefit values indicate that lipegfilgrastim is cost-effective compared to pegfilgrastim. On the other hand, negative incremental net monetary benefit values indicate that lipegfilgrastim is not cost-effective compared to pegfilgrastim. Up to a price point of $€ 1,500$, all incremental net monetary benefit value are greater than zero. At higher price point, lipegfilgrastim shows to no longer be cost-effective for some age groups.

complications (i.e., SN, FN, and infection) health professionals deal with in their practice, those for which treatment algorithms and guidelines have been developed and that impact the most the patients (Aapro et al., 2006, 2011; Freifeld et al., 2011).

The results of our study aligned with Kulikov et al. (2016) but disagree with those obtained by Fust et al. (2015, 2016), who found pegfilgrastim to be dominant when compared to lipegfilgrastim. This difference in conclusion may arise from the study design. From a clinical standpoint, Fust et al.'s model was populated with an OR of 1.39 for the risk of $\mathrm{FN}$ in lipegfilgrastim vs. pegfilgrastim. As mentioned earlier, Wang et al. reported an OR of 1.39 as a result of an MTC and an OR of 0.98 as a result of the direct comparison between lipegfilgrastim and pegfilgrastim in patients with breast cancer only, both risk estimates being non-statistically significant (Wang et al., 2015). By not relying on the head-to-head trial comparing lipegfilgrastim and pegfilgrastim and by using an OR of 1.39 that stem from an indirect and MTC analyses that lack validity (Lehmacher et al., 2016), the incremental savings and utilities reported by Fust et al. may have been overestimated. Our 
analysis aligns with the requirements of leading institutions for health technology assessment (HTA) such as the Belgian KCE (Cleemput et al., 2012), the Canadian Agency for Drugs and Technology in Health (CADTH) (CADTH, 2006), the National Institute for Health and Clinical Excellence NICE, 2013) and the German Institute for Quality and Efficiency in Health Care (IQWIG) (IQWIG, 2012) that have a preference for data from head-to-head randomized controlled trials. Indirect treatment comparison methods may be used if data from head-to-head trials are not available.

Inconsistencies were further noted in Fust et al.'s model when considering costs. Consistent with the clinical effects and the potential for leucocytosis, white blood cell counts should be performed at regular intervals during therapy for both pegfilgrastim and lipegfilgrastim (Lonquex, 2015; Neulasta, 2015). However, this was applied only to lipegfilgrastim in Fust et al.'s model, at the rate of five complete blood counts vs. only one complete blood count prior chemotherapy with pegfilgrastim, potentially overestimating lipegfilgrastim treatment costs. Finally, outpatient FN costs in Fust et al. were as per the USA setting whilst our analysis reflects the Belgian clinical practice.

It could also be argued that the current model differs from Fust et al. in its structure and the selected population. Indeed, the current study focuses on stage II-IV breast cancer patients, whereas Fust et al. reported data on stage II breast cancer patients.

There are several limitations to the current study, the most important one being that currently, there is no direct clinical evidence that CIN leads to clinically recognized chemotherapy delay, lower RDI or poorer survival. However, it could be considered that this was well mitigated in the model as clinical data were used wherever possible. As such, similarity in the use of antibiotics or the fact that almost all patients had received the planned chemotherapy dose in both treatment arms were well reflected in the model. Next, resource use data were obtained in fine from only seven oncologist, holding the potential of a nonrepresentative assessment of resource use. Post-chemotherapy costs were assumed to be zero given that the cost of GCSFs and associated costs were captured in the chemotherapy model (model 1). In addition, there is limited data concerning the impact of RDI on resource utilization and associated costs. Furthermore, the treatment costs for bacteraemia, sepsis, pneumonia, and fungal infection were considered independently. However, such infections are not mutually exclusive. Other types of infection (urinary tract infections, skin and deep tissue infections, mucosal infections, upper respiratory tract infections, etc.) may occur. Sensitivity analyses indicated that costs for treating infections as a result of $\mathrm{SN}$ or $\mathrm{FN}$ events and the relative incidence of type of infection were not drivers of the

\section{REFERENCES}

Aapro, M. S., Bohlius, J., Cameron, D. A., Dal, L. L., Donnelly, J. P., Kearney, N., et al. (2011). 2010 update of EORTC guidelines for the use of granulocytecolony stimulating factor to reduce the incidence of chemotherapy-induced febrile neutropenia in adult patients with lymphoproliferative disorders and solid tumours. Eur. J. Cancer 47, 8-32. doi: 10.1016/j.ejca.2010.10.013 incremental costs. Importantly, translating the granulocyte levels into a risk of infection was based on patients with leukemia (Bodey et al., 1966) given the lack of data in patients with breast cancer.

Our analysis considered the payer's perspective, whereas a societal perspective may be important in other circumstances (Weinstein et al., 1996). Including indirect costs, such as patient time, caregiver costs and lost productivity may improve the costeffectiveness of lipegfilgrastim compared to pegfilgrastim. Finally, although patients with chemotherapy dose delay have about one percent risk of relapse (data on file), relapse was not captured in the present model.

In conclusion, this analysis shows that, for equivalent drug costs, lipegfilgrastim is a dominant strategy compared to pegfilgrastim for the management of patients with stage II-IV breast cancer. Lipegfilgrastim shows to be cost-effective up to $€ 1,500$ across all age bands and cancer stages, compared to the current price of $€ 1,169$.

\section{AUTHOR CONTRIBUTIONS}

This study was carried out in collaboration with all authors. EA and EM conceived and designed the study in consultation with all authors. EA, EM, IJ, and SS were involved in the data collection. EA developed the model and carried out the data analysis. EA, EM, IJ and SS interpreted the results. EA, EM, and IJ wrote a full report based on which SS wrote the draft manuscript. This draft manuscript was revised by EA, EM, and IJ, and all authors approved the final version.

\section{FUNDING}

The study sponsor was not involved in study design, data collection, data analysis and interpretation, writing of the manuscript, and the decision to submit for publication. The corresponding author had final responsibility for the decision to submit for publication.

\section{ACKNOWLEDGMENTS}

The authors would like to thank the following participants of the Delphi panel: Prof. Dr. Daan Dierickx (UZ Leuven), Dr. Kevin Punie (UZ Leuven), Prof. Jean Klastersky (Institut Jules Bordet), Dr. Isabelle Vande Broek (AZ Nikolaas), Dr. Christof Vulsteke (AZ Maria Middelares), Dr. Peter Vuylsteke (Ste ElisabethNamur), Dr. Cornelia Ros (Institut Jules Bordet), Dr. Greet Bries (AZ Turnhout), Dr. Inge Vrelust (AZ Turnhout), Dr. Philippe Mineur (GH de Charleroi), Dr. Marco Gizzi (CNDG Gosselies/GH de Charleroi).

Aapro, M. S., Cameron, D. A., Pettengell, R., Bohlius, J., Crawford, J., Ellis, M., et al. (2006). EORTC guidelines for the use of granulocyte-colony stimulating factor to reduce the incidence of chemotherapy-induced febrile neutropenia in adult patients with lymphomas and solid tumours. Eur. J. Cancer 42, 2433-2453. doi: 10.1016/j.ejca.2006.05.002

Annemans, L. J., Vanoverbeke, N., Caekelbergh, K., Van Belle, S., Cocquyt, V., and Standaert, B. (2001). PMI6: estimating and comparing resource use and cost of 
G-CSF use in chemotherapy with the activity-based costing (ABC) method in three settings. Value Health 4:423. doi: 10.1016/S1098-3015(11)71540-6

Bodey, G. P., Buckley, M., Sathe, Y. S., and Freireich, E. J. (1966). Quantitative relationships between circulating leukocytes and infection in patients with acute leukemia. Ann. Intern. Med. 64, 328-340. doi: 10.7326/0003-4819-64-2-328

Bonadonna, G., Moliterni, A., Zambetti, M., Daidone, M. G., Pilotti, S., Gianni, L., et al. (2005). 30 years' follow up of randomised studies of adjuvant CMF in operable breast cancer: cohort study. BMJ 330:217. doi: $10.1136 / \mathrm{bmj} .38314 .622095 .8 \mathrm{~F}$

Bond, T. C., Mueller, U., Barnes, G., Gennero, R., Tang, B., and Schwartzberg, L. (2015). Lipegfilgrastim for reduction of chemotherapy-induced neutropenia related events: a meta-analysis. Value Health 18:A434. doi: $10.1016 /$ j.jval.2015.09.1041

Bondarenko, I., Gladkov, O. A., Elsaesser, R., Buchner, A., and Bias, P. (2013). Efficacy and safety of lipegfilgrastim versus pegfilgrastim: a randomized, multicenter, active-control phase 3 trial in patients with breast cancer receiving doxorubicin/docetaxel chemotherapy. BMC Cancer 13:386. doi: 10.1186/1471-2407-13-386

Bretzel, R. L. Jr., Cameron, R., Gustas, M., Garcia, M. A., Hoffman, H. K., Malhotra, R., et al. (2009). Dose intensity in early-stage breast cancer: a community practice experience. J. Oncol. Pract. 5, 287-290. doi: 10.1200/JOP.091036

Buchner, A., Lammerich, A., Abdolzade-Bavil, A., Muller, U., and Bias, P. (2014). Lipegfilgrastim: pharmacodynamics and pharmacokinetics for body-weightadjusted and $6 \mathrm{mg}$ fixed doses in two randomized studies in healthy volunteers. Curr. Med. Res. Opin. 30, 2523-2533. doi: 10.1185/03007995.2014.962131

CADTH (2006). Guidelines for the Economic Evaluation of Health Technologies: Canada, 3rd Edn. Ottawa, ON: Canadian Agency for Drugs and Technologies in Health.

CBIP-BCFI BCfPI (2015). Available online at: http://www.cbip.be/ (Dec 25, 2015)

Chan, K. K., Siu, E., Krahn, M. D., Imrie, K., and Alibhai, S. M. (2012), Cost-utility analysis of primary prophylaxis versus secondary prophylaxis with granulocyte colony-stimulating factor in elderly patients with diffuse aggressive lymphoma receiving curative-intent chemotherapy. J. Clin. Oncol. 30, 1064-1071. doi: 10.1200/JCO.2011.36.8647

Chirivella, I., Bermejo, B., Insa, A., Perez-Fidalgo, A., Magro, A., Rosello, S., et al. (2009). Optimal delivery of anthracycline-based chemotherapy in the adjuvant setting improves outcome of breast cancer patients. Breast Cancer Res. Treat. 114, 479-484. doi: 10.1007/s10549-008-0018-1

Cleemput, I., Neyt, M., Van de Sande, S., and Thiry, N. (2012). Belgian Guidelines for Economic Evaluations and Budget Impact Analyses, 2nd Edn., Health Technology Assessment (HTA). KCE Report 183C, Belgian Health Care Knowledge Center (KCE).

Crawford, J., Dale, D. C., and Lyman, G. H. (2004). Chemotherapy-induced neutropenia: risks, consequences, and new directions for its management. Cancer 100, 228-237. doi: $10.1002 / \mathrm{cncr} .11882$

Crawford, J., Ozer, H., Stoller, R., Johnson, D., Lyman, G., Tabbara, I., et al. (1991). Reduction by granulocyte colony-stimulating factor of fever and neutropenia induced by chemotherapy in patients with small-cell lung cancer. N. Engl. J. Med. 325, 164-170. doi: 10.1056/NEJM199107183250305

Federal Reserve Bank of St.Louis (2015). Harmonized Index of Consumer Prices: Health for Belgium. Available online at: https://research.stlouisfed.org/ (Dec 12, 2015)

Freifeld, A. G., Bow, E. J., Sepkowitz, K. A., Boeckh, M. J., Ito, J. I., Mullen, C. A., et al. (2011). Clinical practice guideline for the use of antimicrobial agents in neutropenic patients with cancer: 2010 update by the infectious diseases society of america. Clin. Infect. Dis. 52, e56-e93. doi: 10.1093/cid/ciq147

Fust, K., Li, X., Maschio, M., Barron, R., Weinstein, M. C., Parthan, A., et al. (2014). Cost-effectiveness of prophylaxis treatment strategies for febrile neutropenia in patients with recurrent ovarian cancer. Gynecol. Oncol. 133, 446-453. doi: 10.1016/j.ygyno.2014.03.014

Fust, K., Li, X., Maschio, M., Villa, G, Parthan, A., Barron, R., et al. (2015). Cost-effectiveness of primary prophylaxis with pegfilgrastim vs lipegfilgrastim to reduce the incidence of febrile neutropenia in patients with early stage breast cancer or non-Hodgkin lymphoma. Value Health 3:A204. doi: 10.1016/j.jval.2015.03.1181

Fust, K., Li, X., Maschio, M., Villa, G, Parthan, A., Barron, R., et al. (2016). cost-effectiveness analysis of prophylaxis treatment strategies to reduce the incidence of febrile neutropenia in patients with early-stage breast cancer or non-hodgkin lymphoma. Pharmacoeconomics 35, 1-14. doi: 10.1007/s40273-016-0474-0

Gladkov, O. A., Buchner, A., Bias, P., Muller, U., and Elsasser, R. (2016). Chemotherapy-associated treatment burden in breast cancer patients receiving lipegfilgrastim or pegfilgrastim: secondary efficacy data from a phase III study. Support. Care Cancer 24, 395-400. doi: 10.1007/s00520-015-2803-9

Gold, H. T., Hall, M. J., Blinder, V., and Schackman, B. R. (2009). Cost effectiveness of pharmacogenetic testing for uridine diphosphate glucuronosyltransferase 1A1 before irinotecan administration for metastatic colorectal cancer. Cancer 115, 3858-3867. doi: 10.1002/cncr.24428

Guariglia, R., Martorelli, M. C., Lerose, R., Telesca, D., Milella, M. R., and Musto, P. (2016). Lipegfilgrastim in the management of chemotherapy-induced neutropenia of cancer patients. Biologics 10, 1-8. doi: 10.2147/BTT.S58597

Hoggatt, J., Tate, T. A., and Pelus, L. M. (2015). Role of lipegfilgrastim in the management of chemotherapy-induced neutropenia. Int. J. Nanomed. 10, 2647-2652. doi: 10.2147/IJN.S55796

IQWIG (2012). Importance of Results from Indirect Comparisons. Cologne: Joint Statement from IQWiG, GMDS and IBS-DR. (Accessed January 1, 2017).

Johnson, P., Bancroft, T., Barron, R., Legg, J., Li, X., Watson, H., et al. (2014). Discrete choice experiment to estimate breast cancer patients' preferences and willingness to pay for prophylactic granulocyte colonystimulating factors. Value Health 17, 380-389. doi: 10.1016/j.jval.2014. 01.002

Kuderer, N. M., Dale, D. C., Crawford, J., and Lyman, G. H. (2007). Impact of primary prophylaxis with granulocyte colony-stimulating factor on febrile neutropenia and mortality in adult cancer patients receiving chemotherapy: a systematic review. J. Clin. Oncol. 25, 3158-3167. doi: 10.1200/JCO.2006.08.8823

Kuderer, N. M., Dale, D. C., Crawford, J., Cosler, L. E., and Lyman, G. H. (2006). Mortality, morbidity, and cost associated with febrile neutropenia in adult cancer patients. Cancer 106, 2258-2266. doi: 10.1002/cncr.21847

Kulikov, A. Y., Ugrekhelidze, D. T., Larionova, V. B., and Snegovoy, A. V. (2016). Pharmacoeconomic analysis of the use of ganulocyte colony-stimulating factor drugs in prophylaxis of febrile neutropenia in cancer patients under healthcase settings in the Russian Federation. Pharmacoeconomics Theory Practice 1, 195-201.

Lathia, N., Isogai, P. K., De, A. C., Smith, T. J., Cheung, M., Mittmann, N., et al. (2013). Cost-effectiveness of filgrastim and pegfilgrastim as primary prophylaxis against febrile neutropenia in lymphoma patients. J. Natl. Cancer Inst. 105, 1078-1085. doi: 10.1093/jnci/djt182

Lehmacher, W., Klasser, M., and Duering, A. (2016). Letter to the editor: no increased febrile neutropenia risk to cancer patients receiving lipegfilgrastim-correction of a systematic review and meta-analysis of randomized controlled trials with G-CSF. Support. Care Cancer 24, 1935-1937. doi: 10.1007/s00520-016-3116-3

Leonard, K. (2012). A European survey relating to cancer therapy and neutropenic infections: nurse and patient viewpoints. Eur. J. Oncol. Nurs. 16, 380-6. doi: 10.1016/j.ejon.2011.08.004

Leonard, R. C., Miles, D., Thomas, R., and Nussey, F. (2003). Impact of neutropenia on delivering planned adjuvant chemotherapy: UK audit of primary breast cancer patients. Br. J. Cancer 89, 2062-2068. doi: 10.1038/sj.bjc.6601279

Lonquex (2015). Summary of Product Characteristics.

Lyman, G. H. (2008). Undertreatment of cancer patients with chemotherapy is a global concern. J. Oncol. Pract. 4, 114-115. doi: 10.1200/JOP.0831502

Lyman, G. H. (2009). Impact of chemotherapy dose intensity on cancer patient outcomes. J. Natl. Compr. Canc. Netw. 7, 99-108. doi: 10.6004/jnccn.2009.0009

Lyman, G. H., and Rolston, K. V. (2010). How we treat febrile neutropenia in patients receiving cancer chemotherapy. J. Oncol. Pract. 6, 149-52. doi: 10.1200/JOP.091092

Lyman, G. H., Lalla, A., Barron, R. L., and Dubois, R. W. (2009). Cost-effectiveness of pegfilgrastim versus filgrastim primary prophylaxis in women with earlystage breast cancer receiving chemotherapy in the United States. Clin. Ther. 31, 1092-1104. doi: 10.1016/j.clinthera.2009.05.003

Lyman, G. H., Morrison, V. A., Dale, D. C., Crawford, J., Delgado, D. J., and Fridman, M. (2003). Risk of febrile neutropenia among patients with intermediate-grade non-Hodgkin's lymphoma receiving CHOP chemotherapy. Leuk. Lymphoma 44, 2069-2076. doi: 10.1080/10428190310001 19262 
Massoudi, M., Balk, M., Yang, H., Bui, C. N., Pandya, B. J., Guo, J., et al. (2017). Number needed to treat and associated incremental costs of treatment with enzalutamide versus abiraterone acetate plus prednisone in chemotherapynaïve patients with metastatic castration-resistant prostate cancer. J. Med. Econ. 20, 121-128. doi: 10.1080/13696998.2016.1229670

Mhaskar, R., Clark, O. A. C., Lyman, G., Engel Ayer Botrel, T., Morganti Paladini, L., and Djulbegovic, B. (2014). Colony-stimulating factors for chemotherapy-induced febrile neutropenia. Cochrane Database Syst. Rev. CD003039. doi: 10.1002/14651858.CD003039.pub2

Mitchell, S., Li, X., Woods, M., Garcia, J., Hebard-Massey, K., Barron, R., et al. (2016). Comparative effectiveness of granulocyte colony-stimulating factors to prevent febrile neutropenia and related complications in cancer patients in clinical practice: a systematic review. J. Oncol. Pharm. Pract. 22, 702-716. doi: $10.1177 / 1078155215625459$

Mucenski, J. W., and Shogan, J. E. (2003). Maximizing the outcomes in cancer patients receiving chemotherapy through optimal use of colony-stimulating factor. J. Manag. Care Pharm. 9, 10-14. doi: 10.18553/jmcp.2003.9.s2.10

National Institute for Health and Care Excellence (2013). Guide to the Methods of Technology Appraisal 2013 [Internet]. London: National Institute for Health and Care Excellence (NICE); Process and Methods Guides No. 9.

National Institute for Health and Disability Insurance (RIZIV-INAMI) (2015a). Nomensoft. Available online at: https://www.riziv.fgov.be/webprd/appl/pnomen/search.aspx?lg=N (Accessed Dec 25, 2015).

National Institute for Health and Disability Insurance (RIZIV-INAMI) (2015b). Price of An Inpatient Day. Brussels: National Institute for Health and Disability Insurance (RIZIV-INAMI). (Accessed December 8, 2015).

Neulasta (2015). Summary of Product Characteristics.

Pettengell, R., Johnsen, H. E., Lugtenburg, P. J., Silvestre, A. S., Duhrsen, U., Rossi, F. G., et al. (2012). Impact of febrile neutropenia on R-CHOP chemotherapy delivery and hospitalizations among patients with diffuse large B-cell lymphoma. Support. Care Cancer 20, 647-652. doi: 10.1007/s00520-0111306-6

Pettengell, R., Schwenkglenks, M., Leonard, R., Bosly, A., Paridaens, R., Constenla, M., et al. (2008). Neutropenia occurrence and predictors of reduced chemotherapy delivery: results from the INC-EU prospective observational European neutropenia study. Support. Care Cancer 16, 1299-1309. doi: 10.1007/s00520-008-0430-4

Peura, P., Martikainen, J., Soini, E., Hallinen, T., and Niskanen, L. (2008). Cost-effectiveness of statins in the prevention of coronary heart disease events in middle-aged Finnish men. Curr. Med. Res. Opin. 24, 1823-1832. doi: 10.1185/03007990802144705

Ramsey, S. D., Liu, Z., Boer, R., Sullivan, S. D., Malin, J., Doan, Q. V., et al. (2009). Cost-effectiveness of primary versus secondary prophylaxis with pegfilgrastim in women with early-stage breast cancer receiving chemotherapy. Value Health 12, 217-225. doi: 10.1111/j.1524-4733.2008.00434.x
Rutkowski, J., Derylo, L., Fedyna, M., Plisko, R., Lis, J., and Wladysiuk, M. (2010). PCN83 Cost-effectiveness of lenograstym on neutropenia duration in adults receiving chemotherapy for solid tumors or lymphomas. Value Health 13:A39. doi: 10.1016/S1098-3015(10)72172-0

Saloustros, E., Tryfonidis, K., and Georgoulias, V. (2011). Prophylactic and therapeutic strategies in chemotherapy-induced neutropenia. Expert Opin. Pharmacother. 12, 851-863. doi: 10.1517/14656566.2011.541155

Shayne, M., Crawford, J., Dale, D. C., Culakova, E., and Lyman, G. H. (2006). Predictors of reduced dose intensity in patients with early-stage breast cancer receiving adjuvant chemotherapy. Breast Cancer Res. Treat. 100, 255-262. doi: 10.1007/s10549-006-9254-4

SMC. Scottish Medicines Consortium (2011). Filgrastim, 30 Million Units (300 Micrograms)/0.5 ml, 48 Million Units (480 Micrograms) $/ 0.5 \mathrm{ml}$, Solution for Injection or Infusion in Pre-Filled Syringe (Zarzio $\left.{ }^{\circledR}\right)$. Glasgow: SMC. Scottish Medicines Consortium.

The Cochrane Collaboration (2011). Cochrane Handbook for Systematic Reviews of Interventions, Version 5.1.0. (Accessed Jan 30, 2017)

Therapeutic Goods Administration (2011). Australian Public Assessment Report for Filgrastim. Proprietary Product Name: Nivestim, Sponsor: Hospira Pty Ltd.

Trillet-Lenoir, V., Green, J., Manegold, C., Von, P. J., Gatzemeier, U., Lebeau, B., et al. (1993). Recombinant granulocyte colony stimulating factor reduces the infectious complications of cytotoxic chemotherapy. Eur. J. Cancer 29A, 319-324. doi: 10.1016/0959-8049(93)90376-Q

Wang, L., Baser, O., Kutikova, L., Page, J. H., and Barron, R. (2015). The impact of primary prophylaxis with granulocyte colony-stimulating factors on febrile neutropenia during chemotherapy: a systematic review and metaanalysis of randomized controlled trials. Support. Care Cancer 23, 3131-3140. doi: 10.1007/s00520-015-2686-9

Weinstein, M. C., Siegel, J. E., Gold, M. R., Kamlet, M. S., and Russell, L. B. (1996). Recommendations of the Panel on Cost-effectiveness in Health and Medicine. JAMA 276, 1253-1258. doi: 10.1001/jama.1996.03540150055031

Whyte, S., Cooper, K. L., Stevenson, M. D., Madan, J., and Akehurst, R. (2011). Cost-effectiveness of granulocyte colony-stimulating factor prophylaxis for febrile neutropenia in breast cancer in the United Kingdom. Value Health 14, 465-474. doi: 10.1016/j.jval.2010.10.037

Conflict of Interest Statement: EA, EM, and IJ are employees of Deloitte and SS is an employee of KU Leuven. Deloitte in collaboration with KU Leuven received an unconditional grant from TEVA to carry out this study.

Copyright (C) 2017 Akpo, Jansen, Maes and Simoens. This is an open-access article distributed under the terms of the Creative Commons Attribution License (CC BY). The use, distribution or reproduction in other forums is permitted, provided the original author(s) or licensor are credited and that the original publication in this journal is cited, in accordance with accepted academic practice. No use, distribution or reproduction is permitted which does not comply with these terms. 